\title{
23
}

\section{Importancia del juicio monitorio laboral en Chile}

\author{
The importance of labor trial of payment \\ procedures in Chile
}

\section{RESUMEN}

El presente artículo, resume la importancia del juicio monitorio laboral en Chile. La experiencia chilena, ha sido útil para el Derecho mexicano en aspectos de fondo. Sin embargo, es relevante tomar en cuenta no solo los aspectos sustantivos, sino también los procesales. Contiene una reseña introductoria a este tipo de procedimientos, cómo lo han enfrentado las Oficinas de Defensa Laboral chilenas, y además su relevancia para los actores jurídicos involucrados: empleadores, trabajadores, y abogados.

\section{PALABRAS CLAVE}

Derecho Procesal, Derecho Laboral, Derecho Procesal Laboral, Procedimiento Monitorio Laboral chileno.

\begin{abstract}
The present article summarizes the importance of labor trial of payment procedures in Chile. The Chilean experience has been very helpful for the Mexican Law in background aspects. However its important to take into consideration not only the substantive aspects, but also the procedure aspects. They contain an introductory review of the procedures which the Chilean labor officers have faced and also the important relevant for the judicial actors involved, employees, workers and attorneys.
\end{abstract}

\section{KEYWORDS}

Procedural Law, Labor Law, Procedural Labor Law, Chilean Labor Payment Procedures.

\section{RENÉ DAVID NAVARRO ALBIÑA}

Abogado Defensor Laboral Corporación de Asistencia Judicial CAJVAL. Copiapó, Chile. Secretario General Haimaitier Institute Chile. Vocal Internacional Asociación Iberoamericana de Juristas de Derecho del Trabajo y la Seguridad Social "Guillermo Cabanellas". r.navarro@hii.cl 


\section{INTRODUCCIÓN}

El nuevo sistema procesal laboral chileno recoge la vasta experiencia del Derecho Comparado*, en donde (utilizando simplificadas fórmulas) se acorta el camino a la sentencia definitiva, generando juicio contradictorio, en la medida que surja oposición (reclamo) del afectado. Este nuevo instituto, es teleológicamente tributario del principio de celeridad procesal, para que (en breve tiempo) con una mínima intervención del órgano jurisdictor, y como ya lo expresamos, admite fase litigiosa en la medida que exista reclamación (arts. 496 y ss. Código del Trabajo). Su consagración legislativa, no estuvo exenta de dificultades ni de discusión, y su primer diseño (Ley $N^{\circ} 20.087$ ) fue sustituido por la Ley Nº 20.260 (Tapia Guerrero, 2008, pp. 121 y ss.).

En términos generales (Rodríguez, 1958, p. 99), el procedimiento monitorio puede definirse como un juicio especial, que se abre con una orden o mandato de pago que expide el órgano jurisdiccional, a solicitud fundada del actor y sin audiencia del demandado, emplazando a este último para que, dentro de un plazo fatal, haga pago de lo reclamado o se oponga. La no oposición, transforma el mandato jurisdiccional en sentencia firme, la oposición abre un breve litigio. La voz monitorio procede del latín monitorius, y el Diccionario de la Lengua de la Real Academia Española, define la palabra monitorio como

* Haciendo breve referencia de la legislación comparada, conviene tener presente en este sentido los siguientes ordenamientos jurídicos: el austro-germánico, el italiano, el suizo, el español, y el uruguayo. Crf. Rodríguez, F. E. "E, procedimiento monitorio", Revista de la Facultad de Derecho de México, Tomo VIII, N³0, UNAM, abriljunio, Ciudad de México, 1958, pp. 97 y ss. También aplicable en Brasil, Japón, y otros países de la U.E. Vide. Correa Delcaso, J. P. (2000). El Proceso Monitorio de la Nueva Ley. Barcelona: Editorial Bosch. aquello que sirve para avisar o amonestar. En términos jurídicos, monitorio deriva de la noción del mandato de monición con el que se inicia el proceso (Calamandrei, 1953, p. 19). Para Fausto Rodríguez (salvo una referencia histórica que atribuye a James Goldschmidt, y que hace ubicar este procedimiento en papiros de la Grecia clásica) su origen, aceptado en términos unánimes por los ius procesalistas', viene constituido por algunas prácticas procedimentales medievales tardías (s. XIV-XVI) del período franco-germánico, y por el proceso ítalo-canónico contemporáneo al anterior (Rodríguez, 1958, p. 101).

El procedimiento monitorio en la experiencia comparada, ha facilitado con celeridad el resguardo efectivo de derechos, y simultáneamente brinda una alternativa válida para la justicia mediante un tratamiento especial de la rebeldía, que ocasiona elevados costos en tiempo, esfuerzo y recursos económicos (Pérez, 2006, pp. 205-235).

\section{Importancia del procedimiento monitorio para las Oficinas de Defensa Laboral en Chi- le (ODL)*}

Uno de los principales criterios de focaliza-

- Giuseppe Chiovenda (1872-1937), y también Goldschmidt (1874-1940).

* ODL. Las Oficinas de Defensa Laboral, dependen de la Subsecretaría de Justicia, a través de las Corporaciones de Asistencia Judicial existentes en el país, y que son las Corporaciones de las regiones de Tarapacá y Antofagasta (que cubre las regiones XV, I, y II: www.cajta.cl); región de Valparaíso (que cubre las regiones III, IV y V: www. cajval.cl); Metropolitana (que cubre las regiones XIII, VI, VI y XII: www.cajmetro.cl) y de la Región del Bío Bío (que cubre las regiones VIII, IX, XIV, X, y XI: www.cajbiobio. cl). Las Oficinas de Defensa Laboral, tienen por misión otorgar a todos los trabajadores que no tengan recursos económicos y que focalicen de acuerdo a los criterios de selección, defensa jurídica profesional y especializada, velando por la igualdad ante la ley, el debido proceso y el equilibrio necesario que debe existir ante la sede judicial que corresponda. Cuenta para ello con equipos altamente capacitados, quienes han sido preparados para defender a los trabajadores en los diferentes procedimientos que contempla el nuevo sistema procesal laboral (Cfr. cajval.cl). 
ción de las ODL, se basa en que la cuantía o monto a demandar sea igual o menor a $\$ 2.692 .800$ pesos chilenos (US\$ 5.601), sin contar los aumentos y recargos legales. Esta base, que refiere un factor de atención de estas oficinas de abogados especializados en defensa laboral, por regla general coincide con los montos exigidos por la Ley para ventilar el pleito a través de un juicio monitorio. En efecto, el artículo 496 del Código del Trabajo (CT), señala que se aplica el procedimiento monitorio, respecto de las contiendas cuya cuantía sea igual o inferior a diez ingresos mínimos mensuales, sin considerar, en su caso, los aumentos a que hubiere lugar como producto de las indemnizaciones por años de servicios, conforme los incisos quinto y séptimo del artículo 162 del mismo cuerpo legal. Súmese a lo anterior, el otro criterio de focalización que han estandarizado las llamadas ODL: solo se atienden trabajadores cuya última remuneración mensual líquida, sea igual o inferior a $\$ 388.800$ pesos chilenos (US\$ 808). De esta suerte, un número importante de las causas patrocinadas por las ODL del país, son juicios monitorios*.

* El 59,3 \% de las causas atendidas por las Oficinas de Defensa Laboral de la región de Atacama, son juicios monitorios, cifra medida entre abril de 2008 a la misma fecha de 2010; el 21,2 corresponde a juicios de aplicación general, el 19,1 a juicios ejecutivos, y solo el 0,4 \% a procedimientos de tutela laboral. Cfr. Cuenta Pública a propósito del $2^{\circ}$ Aniversario de la Reforma Procesal Laboral, en abril 2010 ODL Atacama. En la implementación de la Reforma Procesal Laboral, fue experiencia piloto a nivel nacional su inicio en la región de Atacama el 31 de marzo de 2008, junto a la región de Magallanes en la misma fecha. El proceso de instalación e implementación, culminó el 31 de agosto de 2009, con la entrada en vigencia de este sistema en la región Metropolitana, última región del país en adoptarlo. Este dato es relevante, toda vez que la primigenia (aunque leve) experiencia de Atacama y Magallanes, son insustituibles a la hora de los balances y análisis, los cuales no pueden ser solo elaborados con base en la mera tecnocracia exenta de praxis.
Importancia de los juicios monitorios para las empresas y especialmente para las Pymes

Obviamente, las grandes empresas cuentan con poderosos staffs o burós de abogados que atienden sus asuntos y juicios, incluidos los laborales. Generalmente, desde la capital nacional, estos staffs monitorean (a través de abogados de las distintas comunas) sus juicios laborales. Los costos de traslado del (o de los) abogado(s) de la capital, a las distintas localidades y comunas donde se ventilen estos procedimientos, son a veces más onerosos que los demandados en juicios monitorios. De esta suerte, en algunos casos, es (tal vez) mucho más pragmático y utilitario para la empresa, dar instrucciones de pago a través de sus agentes locales, en vez de -como señalamos- gastar recursos en traslado del profesional que se desplace desde la capital nacional hacia las diversas comunas del país, máxime en juicios en donde hay poco que discutir (v.gr. demanda de despido carente de causa legal), sabiendo la empresa que no se remitió carta de despido, y cuya circunstancia figura en el acta frente a la Inspección del Trabajo.

Por otro lado, para las PYMES` locales (si-

- Pequeñas y medianas empresas. Incluimos aquí (para efectos del presente trabajo), todas aquellas empresas y personas naturales que (por regla general) no cuentan con un abogado en forma permanente. Según clasificaciones del Ministerio de Economía, una empresa pequeña es la que al año vende productos o servicios por valores entre 2.400 y 25 mil UF, y una empresa mediana vende entre 25 mil UF y 100 mil UF. Cfr. www.economia. cl. Véanse también las siguientes normas (Ley $\mathrm{N}^{\circ} 19.857$, Ley $\mathrm{N}^{\circ} 19.749$, Decreto-Ley $\mathrm{N}^{\circ} 2.974$, Ley $\mathrm{N}^{\circ} \mathrm{s} 20.179$, 20.416 , Decreto-Ley $\mathrm{N}^{\circ} 3.472$, Ley $\mathrm{N}^{\circ} 18.989$, en su título II (art. 7 al 16), y la Ley $N^{\circ} 20.170$.), y el enlace: http://sdi. bcn.cl/boletin/pags/conozca?id_boletin=23\#305 
guiendo el mismo argumento anterior) en un análisis costo-beneficio, es mucho más atractivo, desde el punto de vista económico, pagar la suma demandada en juicio monitorio, que además, incrementar los costos de abogado litigante.

Lo anterior, hace razonar en el sentido que las empresas (cualquiera sean estas) debieran mantener permanentemente un asesor abogado, especialista o experto* en temas laborales, y no solo en temas laborales de fondo o sustanciales, sino sobre todo (hoy más que ayer) debieran mantener abogados asesores en Derecho Procesal Laboral (además de la no menos importante asesoría en Derecho Administrativo o fiscalizador del trabajo, y todo el amplio abanico jurídico que involucra a la Dirección del Trabajo).

La dinámica impuesta por el nuevo sistema de juicios laborales orales, hace que, en algunas ocasiones, el criterio costo $\mathrm{v} / \mathrm{s}$ beneficio, se analice no solo desde la óptica del Derecho sustantivo o de fondo, sino que también, desde el punto de vista procesal y sus consecuencias.

Todo lo dicho precedentemente no vulnera -como tendremos ocasión de analizar más adelante- ni altera de forma alguna, el principio de bilateralidad de la audiencia, ni el de

* Experto, es aquel que tiene trayectoria práctica en alguna actividad científica o técnica. Especialistas, son aquellos que pueden acreditar, a través de estudios de pre y postgrado (post-títulos, magísters, doctorados, postdoctorados) o docencia, conocimientos determinados o capacidad investigativa en alguna ciencia o arte. igualdad de armas, ni mucho menos el principio constitucional del due process of law.

\section{Importancia de los juicios monitorios para los abogados del foro}

No únicamente solo el juicio monitorio, sino también los procesos orales en general, privilegian el resurgimiento, o mejor dicho, el nacimiento de una verdadera cultura jurídica del abogado litigante. Desde el punto de vista eminentemente utilitario, el juicio monitorio trae aparejada una resolución rápida y eficaz al conflicto laboral, lo que permite serias y reales ventajas al abogado en cuanto al cobro de sus honorarios. Siguiendo este razonamiento, los pactos de cuota litis, tanto en su versión positiva, esto es, porcentaje $a$ resultas, cuanto en su versión negativa, vale decir, porcentaje del menor valor condenado, son mucho más efectivos y empíricamente contrastables y medibles. Los clientes (o patrocinados), no solo leen lo que produce su abogado, sino que -además- ven y oyen (perciben in situ) a su abogado desenvolviéndose en la audiencia oral. Permite también, la fracción del servicio profesional, valga decir, el cobro solo por audiencia (particularmente útil para los burós que contratan abogados locales), o el cobro por reclamación, etc. La práctica hará que estas variantes sean mucho más provechosas para todos los operadores jurídicos: jueces, abogados, clientes, empresas, trabajadores, etc.

En general, con los procesos orales renuevan su utilidad la retórica y la lógica, entre otras ciencias y disciplinas auxiliares de la práctica 
forense. La retórica, no tomada aquí en su acepción peyorativa predominante en nuestro tiempo*, esto es, como un ardid o un mero recurso estilístico y hasta pedante, sino que, la retórica entendida como disciplina científica. Las ars o techne de la litigación, no son más que combinaciones de lógica, retórica y lingüística, las cuales -por cierto- deberían ser cultivadas por los abogados del foro, e incluidas, seria, científica y profesionalmente, en los programas de pre y post grado de las escuelas de Derecho del país`.

Siguiendo en este punto a Serrano, las primeras investigaciones sobre el lenguaje (y el Derecho, no cabe duda, es un lenguaje), las llevaron a cabo los retóricos. La palabra, era un arma destinada a influir delante de un tribunal, una asamblea, etc. Un arma decisiva para obtener la victoria en las luchas donde el discurso era decisivo. Gorgias (c. 485 a.C.) señala: quien posee la palabra, posee la espada. La misión del retórico, era forjar maestros en el arte de persuadir. Dicho de

* Sabemos que Sócrates luchó contra los llamados sofistas, padres de la retórica clásica (Gorgias y Cía.). De allí, viene su desprestigio, el que (creemos) es infundado. El mismo Sócrates, no hubiera podido ser conocido por nosotros, sino gracias a la brillante retórica que Platón plasmó en sus Diálogos, particularmente en la Apología de su maestro.

- La retórica como disciplina susceptible de ser enseñada como un arte, se desarrolla en Grecia a partir de las exigencias dialógicas reclamadas por la instauración del sistema democrático. Vide: Covarrubias C., A. (2003). Introducción a la retórica clásica. Una teoría de la argumentación práctica. Santiago: Ediciones Universidad Católica de Chile. El profesor Covarrubias en el prólogo de su texto expresa: "puesto que en los últimos años ha surgido un creciente interés por los estudios sobre la persuasión, no solamente en filosofía y lingüística sino que también en otras disciplinas como el Derecho -aspecto (...) de principal importancia en Chile con motivo de la (...) modificación del procedimiento penal, que sustituye el sistema escrito por el oral- he estimado oportuno ofrecer este libro (...)". otra manera, la retórica es la técnica (arte) que conseguía hacer el discurso consciente de sí mismo, y hacía de la persuasión un fin a alcanzar por medio de una estrategia específica*.

Desde el punto de vista normativo (nomos), el artículo 430 del Código del Trabajo, inaugura (en términos explícitos) el principio de buena fe procesal a nivel legal. Señala tal norma que los actos procesales deberán ejecutarse de buena fe, facultándose al tribunal para adoptar las medidas necesarias para impedir el fraude, la colusión, el abuso del derecho y las actuaciones dilatorias. El juez podrá rechazar de plano aquellas actuaciones que considere dilatorias. Se entenderá por actuaciones dilatorias, todas aquellas que con el solo objeto de demorar la prosecución del juicio sean realizadas o intentadas por alguna de las partes. De la resolución que declare como tal alguna actuación, la parte afectada podrá reponer para que sea resuelta en la misma audiencia.

Ahora bien, desde el punto de vista práctico, en los juicios orales (y el monitorio es una sub-tipología), es más difícil dar pie a leguleyadas y ganancias fáciles": la dinámica y

\footnotetext{
Señala Serrano, que la técnica fundamentada sobre el conocimiento de las causas que generan los efectos de la persuasión, concede un poder indudable a quien la posea: el poder de disponer de las palabras sin necesidad de las cosas, y de disponer de las personas, al disponer de las palabras ... qué rigurosa actualidad tienen estas consideraciones: quien dispone hoy de los medios de comunicación, en definitiva dispone de las personas.

- Para el Diccionario de la Lengua de la Real Academia Española (hoy: www.rae.es), leguleyo, es la persona que aplica el Derecho sin rigor, desenfadadamente, que hace gestiones ilícitas en los juzgados.
} 
rapidez de la litigación las mitigan v.gr. ¿Podemos preparar a un testigo falso?, en vivo y en directo es mucho más difícil mentir, y en los juicios orales se nota, los jueces lo notan, nuestros nuevos jueces lo saben ¿podemos elucubrar traslados de más de 30 páginas sentados en nuestro escritorio? No, por regla general, los traslados se evacúan en el acto y algunos recursos siguen la misma suerte.

Quizá, la visión pesimista del ejercicio de la profesión, de Jeremías Bentham (1748-1832) se morigere en Chile, en este novel siglo XXI, con los procedimientos de que ya disponemos (penal, familia, laboral, y civil, pronto a ver la luz). Según el maestro inglés, la jerga jurídica tenía como objetivo generalmente defender los intereses siniestros de los juristas, cuyo lenguaje y ritos esotéricos constituían una red para atrapar a los comunes mortales (...) en materia de legislación (decía): "las opiniones de los hombres de leyes tienen una propensión peculiar a teñirse de falsedad por obra del interés siniestro". Y así, mientras al interés de los ciudadanos conviene una justicia rápida, al interés siniestro (sinister interests) del abogado, le conviene una administración de justicia lenta; si al interés del ciudadano le convienen unas leyes claras y breves, al hombre de leyes le interesan prolijas y oscuras (Zapatero, 2004, p. LXI).

Podemos decirle hoy a don Jeremías, que los juicios laborales (y en particular los monitorios), y la legislación que los soporta y sustenta, tanto en la nomos como en la praxis, son rápidos y efectivos. Los jueces especializados en materia laboral, proveen las demandas monitorias, de un día para otro, las demandas se pueden remitir por correo electrónico, las resoluciones se pueden notificar por correo electrónico, los exhortos se tramitan electrónicamente, el público en general (y el público jurídico), puede consultar todas las causas y resoluciones a través de la web del poder judicial (www.poderjudicial.cl) y, en el caso de llegar a audiencia de juicio, esta deberá celebrarse dentro de los quince días siguientes a su presentación (art. 500 CT)*. En el evento de llegar a una sentencia, esta se dicta al momento de finalizar la audiencia.

\section{Importancia del procedimiento monitorio para los trabajadores y el ordenamiento ju- rídico}

Se ha señalado (infundadamente, creo) que la reforma laboral privilegia en exceso a los trabajadores, que se rompe en algunos casos la bilateralidad de la audiencia a su favor, que los demandados (empleadores) no tienen suficiente tiempo para defenderse, et cetarae res. Todas esas afirmaciones, no cumplen ningún soporte ni empírico, ni técnico, ni dogmático:. Señalar como fundamento, que más del $90 \%$ de los juicios son ganados por los trabajadores, no es analizar la cifra en

* No con afán de exagerar, señalemos que en la etapa prereforma procesal laboral oral del 2008, podía extenderse un juicio por más de dos y hasta tres años; aunque la nomos hubiere dicho otra cosa. Agreguemos a ello, que las causas eran asistidas -a favor de un importantísimo número de trabajadores- por los postulantes en práctica (egresados de las carreras de Derecho del país) de las Corporaciones de Asistencia Judicial, no por letrados titulados.

- Vide a modo meramente ejemplar, la editorial del Diario El Mercurio de Santiago, de fecha 03 de agosto de 2009, disponible en la web (www.elmercurio.com). 
profundidad. La pregunta y el foco de atención, no solo debe ponerse en el resultado, sino que también en las causas (orígenes), vale preguntarse ¿por qué más del $90 \%$ de los juicios son ganados por los trabajadores? Fuera de contexto, sin duda la cifra alarma, sin embargo, tal cifra es menester situarla en el procedimiento laboral en su conjunto, y no solo en el resultado. Tampoco corresponde acusar a nuestros jueces de parcialidad (falta de imparcialidad): ¿Qué puede hacer un juez frente a un despido sin carta de aviso, y sin pago de las cotizaciones previsionales? ¿Qué debe hacer el juez si el requerido (debidamente emplazado) no concurrió frente a la instancia administrativa, y luego este mismo, no concurrió a la audiencia única de conciliación, contestación y prueba, debidamente emplazado, o bien, no reclamó de la sentencia que acogió las pretensiones en un juicio monitorio? ¿Se puede acusar a ese juez o jueza de falta de imparcialidad, al recoger -en los casos recién propuestos- esas demandas y condenar a esos empleadores?

Agreguemos en este punto (cuestión que precisaremos más adelante), que no es técnicamente correcto hablar de reforma laboral. A partir de 2008 y de 2009 en todo el país, corresponde hablar y referirnos a la reforma procesal en materia laboral. La legislación laboral de fondo (de inspiración y matriz primordialmente ius neoliberal), no ha cambiado mayormente. Estamos en presencia de una reforma adjetiva (no menos trascendente), pero meramente procesal. El derecho de fondo (las obligaciones, derechos y deberes recíprocos entre empleadores y trabajadores) es el mismo. No hay grandes modificaciones como para hablar correctamente de una reforma con el calificativo de laboral. El cambio de paradigma (a la manera de Kuhn) (Kuhn, 2000) se produce en el sistema legal vinculado al procedimiento laboral. Al momento de entrar en vigencia el nuevo modelo*, sin duda se produce un quiebre ostensible con el anterior, desde cualquier punto de vista, como podría ser el criterio cronológico, el criterio técnico (especialización), el criterio de certeza vinculado a la inmediación, etc. El refrán popular (no alcanza para brocardo o aforismo jurídico) "la justicia tarda, pero llega", no es aplicable a materias en donde se reclaman prestaciones de naturaleza alimenticia, como son las remuneraciones de los trabajadores. La justicia que tarda, no es justicia, es una justicia que no resuelve el conflicto de sujetos de carne y hueso.

Respecto a la bilateralidad de la audiencia, del due process of law (ya dijimos) y respecto a los diversos términos de emplazamiento legal, nos referiremos más adelante. Sin embargo, resulta relevante hacer hincapié, en relación a ciertos plazos, que son muy cortos, y que la legislación pre-reforma procesal laboral ya tenía. Me refiero al plazo de caducidad de las acciones derivadas del despido, que es de 60 días hábiles, y el de prescripción de las prestaciones laborales, que es de solo seis meses. Parafraseando a las autoridades del Ejecutivo de la época, al momento de entrada en vigencia del nuevo modelo procesal laboral: "los empleadores que

* Que obviamente solo causó impacto mediático cuando comenzó a regir en Santiago, la capital de Chile. 
respetan la ley, no tienen nada que temer, la ley laboral es la misma, solo modificamos la forma de reclamar en juicio". Piénsese solo en las posibilidades de acceso a la cultura, y por consiguiente, el acceso al conocimiento efectivo de la ley, realizando un versus entre empresas y trabajadores. Obviamente hay de todo en la viña del Señor: empleadores que son celosos y escrupulosos vigilantes de la ley, y aquellos que la violan permanente y flagrantemente*. Valga el siguiente ejemplo

* Diario Atacama (filial regional de El Mercurio), 29 de enero de 2010: “"A la deriva, sin poder alimentarse en más de una semana; durmiendo a la intemperie y sumado a los malos tratos por parte de su empleador". Ese es el relato crudo de 23 temporeros que en condición de ilegalidad llegaron a Copiapó por una mejor calidad de vida. Con estas palabras los inmigrantes aseveran el mal paso que se han llevado por la capital regional de Atacama. La semana pasada, en conjunto con la Dirección del Trabajo, personal de extranjería de la PDI concurrió a las cercanías del fundo [...] de Copiapó, en donde no constataron ningún hecho irregular. Pasaron los días y las declaraciones anónimas sumaban y seguían. Fue el martes 26 de enero cuando funcionarios de la Brigada de Homicidios de la PDI realizaba una búsqueda de personas con requerimiento de los tribunales de justicia cuando constataron la presencia de unos 150 extranjeros apostados en las afueras del fundo, al notar la presencia policial estos se dieron a la fuga. Lograron retener a 23 inmigrantes, a quienes se les solicitó su cédula de identidad y pasaporte, posterior a eso fueron citados al departamento de extranjería de la PDI para regularizar su situación y explicar el hecho. Los 23 inmigrantes de nacionalidad peruana y boliviana relataron que fueron abandonados a su suerte por su empleador. Según el subcomisario, quien tomó declaración a los extranjeros ilegales, estos "habrían sido sacados en dos buses en dirección a Caldera. El contratista los dejó prácticamente botados y asimismo no les pagó". Elsa Machaca, temporera ilegal proveniente de Bolivia corrobora esta aseveración: “Nos sacaron del campamento a las doce y media de la noche con el pretexto de llevarnos a Tierra Amarilla diciéndonos que venía Investigaciones y por eso nos debían esconder. Pero no sabíamos que nos llevaban a Caldera, nos engañaron y nos dejaron botados ahí. Nosotros no tenemos dinero y hace una semana que no comemos", declaró la temporera. De los 23 extranjeros, solamente uno tenía visa de trabajo (...). “Ellos en ningún caso están detenidos, sino que cometieron una infracción al reglamento de extranjería, por tanto cumplimos en tomar los antecedentes y enviarlos a la gobernación provincial y la intendencia que determinará el grado de sanciones que se deben aplicar", sentenció el subcomisario" (sic). Cfr. http://www.diarioatacama.cl/prontus4_nots/site/ artic/20100129/pags/20100129034529.html que no es de ciencia ficción: -“¿Jefe, cuándo van a pagar mi finiquito en la carta esa que me mandaron a la casa hace como un mes? -Mañana llega la respuesta del encargado de Santiago, ven la próxima semana; (próxima semana): -Jefe ¿supo algo de Santiago? -Estamos en eso, no te preocupes, tú sabes que los papeleos demoran; (dos meses después): -iOiga, voy a tener que ir a la Inspección para arreglar el problema!-Anda no más (le responde una secretaria), porque tus papeles ya los tiene el abogado de la empresa en Santiago... -¿YY cuándo cree Ud., Rosita que me van a pagar?"... El final de la historia el lector lo puede intuir. Se insiste, en que la mayoría de los empleadores cumple la ley, y por esa razón no son demandados, solo son demandados aquellos que la vulneran, y por ello, aumentan las cifras de juicios ganados a favor de los trabajadores.

Es muy fácil, ser acusado del pecado capital del sesgo ideológico, no es nuestro afán revitalizar viejas rencillas occisas desde que el muro de Berlín cayó (o eso esperamos en el siglo de las TIC). El procedimiento monitorio es, un procedimiento racional y justo para trabajadores y empleadores: tiempo es dinero. Mientras más rápido, más eficaz para todos los operadores, no solo aquellos operadores del sistema jurídico, sino también los del sistema macro y micro económico en su conjunto.

Sin entrar en polémicas ideológicas de veterana data, no es fácil soslayar (seriamente) el carácter alimentario de la prestación laboral. El fundamento de la existencia de un sistema 
legal, y por cierto procesal, de protección a las remuneraciones, se basa, principalmente, en la naturaleza predominantemente alimentaria que esta tiene. El legislador (de cualquier color político en naciones civilizadas) entiende que para el trabajador la remuneración constituye su medio de subsistencia, por lo que se hace necesario introducir normas ( $y$ por cierto efectivas garantías jurisdiccionales) que permitan que el trabajador perciba la contraprestación debida. Estas normas deben propender a que el dependiente obtenga garantías de pago íntegro y oportuno de la remuneración a que tiene derecho en virtud del contrato de trabajo, y en tanto contrato, no solo obliga a lo que en él se expresa, sino que por la costumbre o la ley, pertenecen a la naturaleza de la obligación; haciéndonos aquí eco, no de un principio post moderno y social de protección laboral, sino que nos remonta al decimonónico, -y de clara y absoluta matriz liberal revolucionaria-francesa del año 1789- principio de ejecución de buena fe de los contratos (Código Civil de Andrés Bello, 1855, artículo 1546)*.

En el Manual de Juicio del Trabajo, de que dispone la Academia Judicial de Chile (de libre acceso en su web www.academiajudicial.cl), se expresa que previo a la entrada en vigencia de la reforma procesal laboral: "existía la convicción, ampliamente compartida por la comunidad ius laboralista, de que el funcionamiento de los mecanismos jurisdiccionales no se ajustaba a los requerimientos de acceso

* E incluso un principio más antiguo de la cultura jurídica occidental: pacta sunct servadae. a la justicia laboral, toda vez que el procedimiento en juicio del trabajo adolecía de una serie de inconvenientes que llevaban a largos procesos, sin que los trabajadores accedieran a una tutela efectiva de sus derechos (...) de nada hubiera servido la modificación del derecho sustantivo si, además, no se introducían profundas modificaciones en las normas del juicio del trabajo" (Tapia Guerrero, 2008, p. 9); se agrega en dicho texto, que luego de un amplio y fructífero debate, en donde participaron académicos, magistrados, abogados litigantes privados, de servicios públicos, etc., se formó el Foro de la Reforma Procesal Laboral y Previsional (FRPLP), cuyas propuestas constituyeron parte importante de los proyectos de ley respectivos y, por cierto, de las diversas etapas de su amplia y transversal discusión parlamentaria.

Sabemos que la norma general y abstracta, y los derechos subjetivos que sustente, son (o podrían ser) meras declaraciones programáticas o catálogos de buenas intenciones, si no van acompañados de efectivas vías jurisdiccionales, de materialización práctica de las mismas. Como señala Antonio M. Lorca (Boletín Mexicano de Derecho Comparado, 2003, pp. 31-557), el proceso como sistema de garantías supone otorgar al ámbito hétero-compositivo de la función jurisdiccional, una respuesta constitucional sustantiva, procesal y de "aquí y ahora" respecto de este (y no de otro) concreto momento, en contraposición con una proyección exclusivamente instrumental atemporal y acrítica del habitual y común "procedimentalismo" de las antiguas leyes de enjuiciamiento. La inter- 
pretación y aplicación de las normas procesales tiene trascendencia constitucional, por cuanto el derecho a la tutela judicial efectiva, obliga a elegir la interpretación de aquella que sea más conforme con el principio pro actione y con la efectividad de las garantías que se integran en esa tutela, de suerte que si la interpretación de la forma procesal no se acomoda a la finalidad de garantía, hasta el punto que desaparezca la proporcionalidad entre lo que la forma demanda y el fin que pretende, olvidando su lógica y razonable concatenación sustantiva, entonces es claro que el derecho fundamental a la tutela efectiva resulta vulnerado.

La reforma procesal laboral, trata de poner al día las exigencias de materialización de una efectiva tutela jurisdiccional de prestaciones que (ya señalamos) tiene carácter alimentario, de sustento vital, máxime en el juicio monitorio donde, por ley, solo se ventilan causas cuya cuantía no supere (a la fecha de hoy) $\$ 1.930 .000$ pesos chilenos (US\$ 4.014), sin contar los aumentos y recargos legales.

Los trabajadores no especulan en sus demandas laborales. Entre perder tiempo en juicios y buscar trabajo, la gran mayoría elige la segunda opción, renunciando incluso a su legítimo interés: el cobro judicial de lo que es suyo. Lo anterior es bastante trascendente a la hora de explicar, más adelante, el eficaz y poderoso mecanismo auto-compositivo que promueve la reforma procesal laboral. La autocomposición no se basa en la teoría "yo gano, tú pierdes" (Neumann \& Morgenstern, 1944), más bien al contrario, se basa en las concesiones recíprocas. En las salidas alternativas a la sentencia laboral, ninguna de las dos partes gana ni pierde, gana la sociedad: se evita un conflicto jurisdiccional.

Finalmente en este punto -y en muy próxima conexión con lo que acabamos de señalardiremos que el jurista trasandino, Carlos Santiago Nino (Nino, 2003), haciendo referencia a Hobbes, expresa que es ineludible un contrato social al que los hombres deben suscribir para satisfacer su propio auto-interés. La vida en el estado de naturaleza es "cruel, brutal y corta", pero los hombres no pueden salir de ella simplemente por acuerdos mutuos (mera autonomía de la voluntad), ya que ellos plantean problemas de acción colectiva -del tipo del que luego fuera llamado el "dilema de los prisioneros"-", ya que cada uno desconfía en que el otro saque ventaja de la violación del acuerdo. De modo que los hombres deben primero acordar el establecimiento de un poder (el del Estado) que luego los fuerce a cumplir con los otros. En otros términos: "cumpla lo que usted mismo se obligó por su propia palabra, y cumpla

\footnotetext{
* "La policía arresta a dos sospechosos. No hay pruebas suficientes para condenarlos y, tras haberlos separado, los visita a cada uno y les ofrece el mismo trato. Si uno confiesa y su cómplice no, el cómplice será condenado a la pena total, diez años, y el primero será liberado. Si uno calla y el cómplice confiesa, el primero recibirá esa pena y será el cómplice quien salga libre. Si ambos confiesan, ambos serán condenados a seis años. Si ambos lo niegan, todo lo que podrán hacer será encerrarlos durante seis meses por un cargo menor". Vide: Hoester, N. (1975). Problemas de ética normativa. Buenos Aires: Editorial Alfa y Patzig, G. (1976). Ética sin metafísica. Buenos Aires: Editorial Alfa, traducidos por el filósofo del Derecho argentino Ernesto Garzón Valdés (1927), y citado por Carlos Santiago Nino (1943-1993), en Ética y derechos humanos. Buenos Aires: Editorial Astrea, 1989, pp. 63 y ss.
} 
también aquello que la Ley -que todos acordamos, incluido usted- ordena" (Navarro, 2011).

\section{REFERENCIAS BIBLIOGRÁFICAS}

Academia Judicial de Chile, Manual de Juicio del Trabajo, redactado por el profesor Francisco Tapia Guerrero, los magistrados Marcia Undurraga Jensen, Álvaro Flores Monardes, y los académicos María Eugenia Montt Retamales y Rodolfo Caballero Muñoz, Instituto de Estudios Judiciales, Santiago, 2008.

Boletín Mexicano de Derecho Comparado, nueva serie, año XXXVI, núm. 107, mayoagosto de 2003, 31-557.

Calamandrei, P. (1953). El procedimiento monitorio. Traducción de Santiago Sentís Melendo. Buenos Aires: Ediciones Jurídicas Europa-América.

Correa Delcaso, J. P. (2000). El proceso monitorio de la Nueva Ley. Barcelona: Editorial Bosch.

Covarrubias C., A. (2003). Introducción a la retórica clásica. Una teoría de la argumentación práctica. Santiago: Ediciones Universidad Católica de Chile.

Hoester, N. (1975). Problemas de ética normativa. Buenos Aires: Editorial Alfa.

Kuhn, T. (2000). La estructura de las revoluciones científicas. Santiago: Fondo de Cultura Económica.
Navarro A., R. D. (2011). El juicio monitorio en el Derecho Procesal chileno. Dogmática y praxis. Chile: Ediciones Jurídicas de Santiago.

Neumann, J. y Morgenstern, O. (1944). Theory of Games and Economic Behavior. New Jersey: Princeton University Press.

Nino, C. S. (1989). Ética y derechos humanos. Buenos Aires: Editorial Astrea.

Nino, C. S. (2003). "Justicia". En: Revista de Filosofía del Derecho DOXA, N¹4, Alicante.

Patzig, G. (1976). Ética sin metafísica. Buenos Aires: Editorial Alfa.

Pérez R., Á. (2006). “En torno al procedimiento monitorio desde el Derecho Procesal comparado europeo: caracterización elementos esenciales y accidentales". Revista de Derecho de Valdivia, $\mathrm{XIX(1),} \mathrm{205-235.}$

Rodríguez, F. E. (1958). "El procedimiento monitorio". Revista de la Facultad de Derecho de UNAM de México, Tomo VIII, N³0, 97 y ss.

Serrano, S. (1999). La lingüística. Su historia y su desarrollo. Barcelona: Editorial Montesinos.

Zapatero, V. (2004). "El arte ilustrado de legislar", en "Nomografía o El arte de redactar leyes" de Jeremy Bentham, Boletín Oficial del Estado. Madrid: Centro de Estudios Políticos y Constitucionales. 
